Available online at : www.refaad.com/CRMI

CRMI 1(1) (2020) : 1-4

Current Research in Microbiology and Infection (CRMI)

Journal Homepage: https://www.refaad.com/views/CRMI/home.aspx

\title{
Bovine Tuberculosis in young heifer
}

\section{Omran Hamdan Alameri*a}

a Faculty of veterinary Medicine, Jordan University of Science and Technology (JUST).

ohma@just.edu.jo

Received: $1^{\text {th }}$ Jul 2020 Revised: 5h Aug2020 Accepted: 9th Oct 2020 DOI: https://doi.org/10.31559/CRMI2020.1.1.1

Abstract: A rare case of bovine tuberculosis in young heifer is reported. Miss diagnosed in several occasions due to lack of diagnostic tools. However; post-mortem lesion diagnosis is paramount. This case may pose public health concern to the farmer and his family.

Keywords: Bovine; Tuberculosis; Pneumonia; Jordan Valley.

${ }^{*}$ Corresponding author

Omran Hamdan Alameri

Faculty of veterinary Medicine, Jordan University of Science and Technology (JUST).

E-mail: ohma@just.edu.jo 


\section{Introduction}

Tuberculosis (TB) is usually a chronic debilitating disease in cattle and caused by Mycobacterium bovis. Animals are infected through ingestion of body fluids, secretion and excretions and food and water. Calves can contract bovine TB when they drink unpasteurised milk from infected cows (Aboukhassib $\mathrm{H}$. et al 2016). The disease is zoonotic; can be transmitted from animals to humans (Ashford D et al 2001). Disease control measures (test and slaughter) are weak in developing countries due to high cost and efforts needed.

\section{Materials and methods}

\section{Case Description:}

A TB case in eleven-month old Holstein young heifer bought by a framer from a local small holder farmer in Jordan valley is described. At the time of purchase (age was three months), the animal was presented with poor body score but normal appetite. Ten days later, the animal showed signs of fever, coughing, and salivation. A veterinarian was consulted and treated the animal for pneumonia. After several days of medications, the signs disappeared. The animal condition was stable until it reached seven months of age where it showed the same previous clinical picture. It was then treated once again for pneumonia and the signs disappeared after medical intervention. When it reached 11 months of age, it showed signs of depression and decreased feed intake. It was given rumen stimulant "vexaprone" and antibiotic "Draxxin" but the animal condition did not improve. Five days later, the animal showed signs of enteritis "black diarrhea", pain "grinding", and complete anorexia. The animal was given antibiotics, vitamins and pain killers but died two days later on.

The animal was examined by a veterinarian after death. The Post-mortem examination showed lobar pneumonia, excessive nodules and abscesses of the intestinal mesentery and liver, intestinal hemorrhages, and omasal impaction (Figure $1 \mathrm{a}, \mathrm{b}, \mathrm{c}$, d).

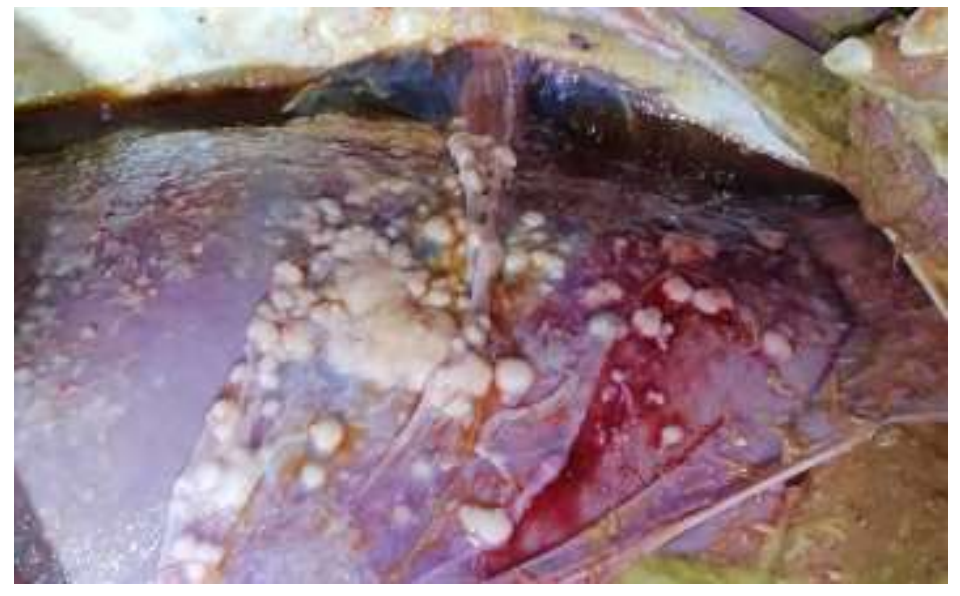

Fig(1a): Nodules on visceral pleura

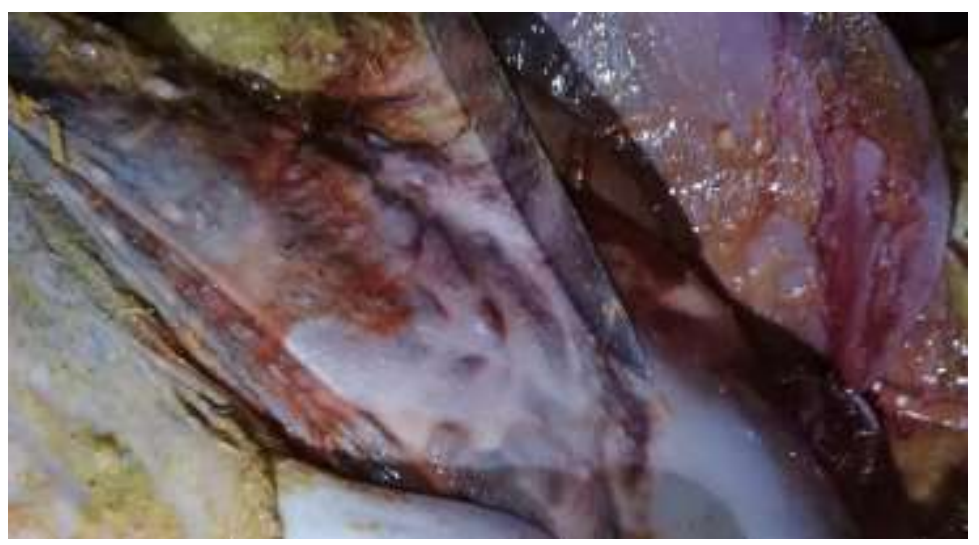

Fig(1b): Haemorrhagic nodules in the thoracic cavity 


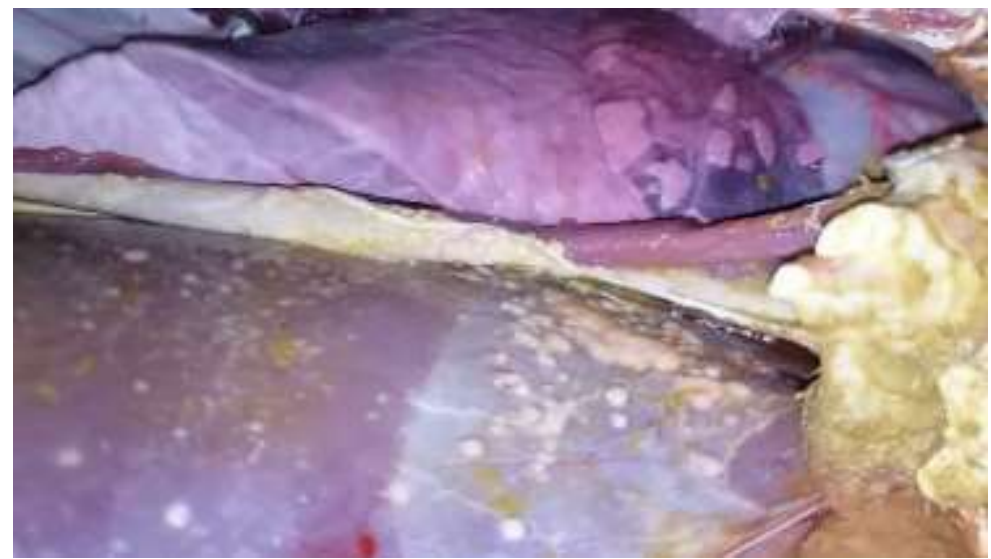

Fig(1c): Nodules and lumps on pleural cavity and lung

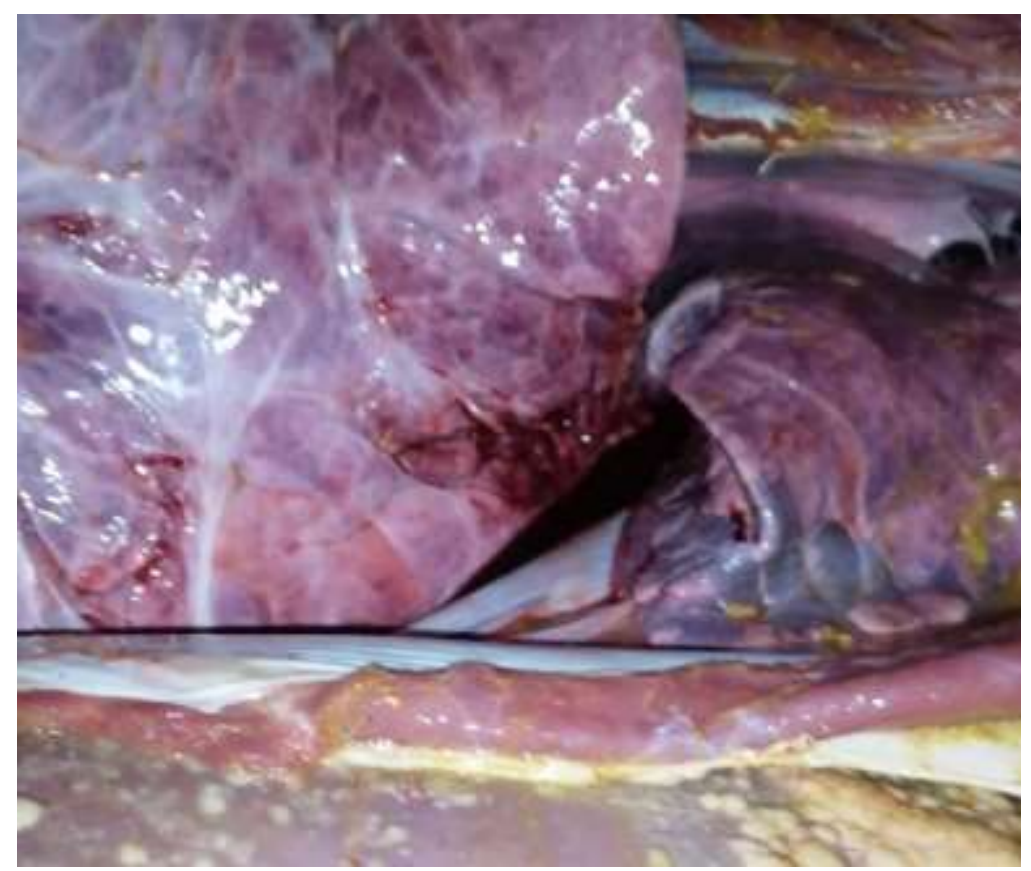

Fig(1d): Chronic pneumonia

The veterinarian diagnosed the case as TB. The seller (a small animal holder) was then called by telephone and asked if he has animals with poor condition for further follow-up. He has one animal that is almost one year old with poor condition. The owner was advised to examine his animals for TB using Tuberculin skin test, boil milk before consumption and isolate the weak and sick animals.

\section{Discussion:}

Post-mortem examination, treatment failure and the course of the disease are highly suggestive of bovine TB. There must be an undetected transmission of TB in the original farm, from where the female calf was purchased (a small farm holder). Several studies reported a correlation between body condition and bovine TB (Tschopp R. et al 2009 and Nega M. et al 2012). In this report the animal was with poor body condition and there was another heifer left with poor condition in the farm. This should have initiated TB test in the farm. We think several factors hampered this; first, the rare cases of TB in young animals that deflected the veterinarian attention to another diagnosis (pneumonia or enteritis) which was based only on clinical signs, Second, the small number of animals owned by the farmer that entails further financial expenses and finally, the lack of diagnostics in such poor, remote area

In cases of bovine $\mathrm{Tb}$, it is expected that medical intervention won't work due to intracellular nature of $M$. bovis and its resistance to antibiotics. These factors and the unexpected occurrence of the condition in young animals due to the chronic presentation of the disease, lead to disease miss diagnosis.

Conflict of Interests: No conflict of interest.

\section{References}

[1] Aboukhassib H., Haraji M., Bouslikhane M. \& Bitar A. (2016). Bovine tuberculosis: clinical presentation 
and diagnosis. I Bacteriol Mycol Open Access, 3(2):214-217

https://doi.org/10.15406/jbmoa.2016.03.00057.

[2] Ashford D. A., E. Whintey, P. Raghunathan \& P. Cosivi. (2001). Epidemiology of selected mycobacteria that infect humans and other animals. Rev. Sci. Tech., 20(1):325-337, https://doi.org/10.20506/rst.20.1.1266.
[3] Nega M., Mazengia H. \& Mekonen G. (2012). Prevalence and zoonotic implications of bovine tuberculosis in Northwest Ethiopia. Int J Med Sci., 2(9): 188-192.

[4] Tschopp R., Schelling E., Hattendorf J., Aseffa A. \& Zinsstag J. (2009). Risk factors of bovine tuberculosis in cattle in rural livestock production systems of Ethiopia. Prev Vet Med, 89(3-4): 205211, https://doi.org/10.1016/j.prevetmed.2009.02.006. 